\title{
Prevalence and factors associated with pedestrian fatalities and serious injuries: case Finland
}

\author{
Fanny Malin ${ }^{1 *}$, Anne Silla ${ }^{1}$ and Miloš N. Mladenović ${ }^{2}$
}

\begin{abstract}
The aim of the study was to examine the prevalence of pedestrian fatalities and serious injuries (MAIS3+) in traffic, and to identify differences in the factors associated with the injury severities. The study included all motor vehiclepedestrian accidents in Finland in 2014-2017 and exposure data from the national travel survey of 2016. The results showed a heightened fatality and serious injury rate specifically for pedestrians aged over 75 years and in rural heartland areas. Furthermore, differences were identified in the current speed limit, municipality type, lighting conditions, vehicle type, area type, accident location, and road conditions between pedestrian fatalities and serious injuries. The main implications of the study are that traffic safety measures should be tailored to local conditions and amended and redirected to account for both fatalities and serious injuries. In order to conduct comparative studies between countries and support the achievement of transport policy objectives, further harmonisation of definitions and data collection procedures for traffic accidents is needed.
\end{abstract}

Keywords: Traffic safety, Crash, Walking, Maximum abbreviated injury scale

\section{Introduction}

According to the European Declaration on Road Safety, the number of fatalities and serious injuries in 2030 should be halved from that in 2020 [66]. At the same time, the target is to raise the share of active and environmentally sustainable travel, such as utility walking and cycling (i.e. for a specific purpose), by changing the properties of the transport system and the built environment [7]. However, in order to encourage systemic behavioural change, safety is an essential precondition for people to travel by active transport modes (e.g. [25, 32]). In Europe, the safety of pedestrians and cyclists is generally better than in other countries but has nonetheless improved at a slower rate than that of vehicle occupants $[9,15,31]$. Thus, there is an important societal need to understand traffic safety conditions in specific areas and

\footnotetext{
* Correspondence: fanny.malin@vtt.fi

${ }^{1}$ VTT Technical Research Centre of Finland Ltd, P.O. Box 1000, Fl-02044 VTT Espoo, Finland

Full list of author information is available at the end of the article
}

to draw lessons for related planning and policymaking mechanisms among relevant stakeholders [10]. One way of understanding a traffic safety situation is to use quantification of traffic accidents. These are defined as accidents occurring on the road with at least one moving vehicle and resulting in at least one person being injured [40]. As such, pedestrian single accidents, such as falling outdoors, are not currently defined as traffic accidents. Although they represent an obvious problem for pedestrian safety (e.g. [33, 53]), this study focuses on motor vehicle-pedestrian accidents, because no official information currently exists on single pedestrian fatalities. The number of traffic accidents relates to exposure, risk and consequence [39]. Exposure represents the amount of activity where an accident can occur, risk is the expected number of accidents per unit of exposure, and consequence is the severity of the accident. Thus, influencing traffic safety relates to changes in any of these three dimensions. Changes in the built environment, such as separation of road users or vehicle speed control, has

\section{Springer Open}

(ㅇ The Author(s). 2020 Open Access This article is licensed under a Creative Commons Attribution 4.0 International License, which permits use, sharing, adaptation, distribution and reproduction in any medium or format, as long as you give appropriate credit to the original author(s) and the source, provide a link to the Creative Commons licence, and indicate if changes were made. The images or other third party material in this article are included in the article's Creative Commons licence, unless indicated otherwise in a credit line to the material. If material is not included in the article's Creative Commons licence and your intended use is not permitted by statutory regulation or exceeds the permitted use, you will need to obtain permission directly from the copyright holder. To view a copy of this licence, visit http://creativecommons.org/licenses/by/4.0/. 
been assessed to reduce the number of motor vehiclepedestrian accidents (e.g. [13, 48, 62]). Additionally, the built environment has an effect on the amount of walking, through variables such as mixed land use, aesthetics and walking infrastructure (e.g. [6, 35, 42]).

Previous research informs us that the pedestrian fatality risk is generally higher for men than for women, with some exceptions in the older age range (over 75 years) (e.g. $[1,27,69])$. When controlling for population size, the risk is higher for men than for women also in the older age groups (e.g. [4, 27]). Looking specifically at age, the risk is higher for younger $(<25$ years $)$ and older ( $>75$ years) pedestrians compared to other age groups (e.g. $[1,27])$. Compared with traffic safety analysis of vehicle accidents, choice of exposure is not as straightforward in regard to pedestrians. Previous studies have, for example, used hours walked (e.g. [27, 30]), kilometres walked (e.g. [3, 11]), number of roads crossed (e.g. $[21,27])$, and number of pedestrians at the crosswalk (e.g. [29]). Regarding location, a majority of pedestrian accidents occur in urban rather than rural areas. Regarding accident severity, fatalities are more common than other severities in rural areas (e.g. [1, 21, 22, 24, 30, $37,68]$ ) and in areas with higher speed limits (e.g. $[14,29,58])$, largely due to the relation between speed and pedestrian injury severity (e.g. [49, 60]). Previous research has also found that pedestrian accident severity is higher for accidents with heavier vehicles (e.g. $[5,30,50])$. Regarding weather and road conditions, injury severity generally increases with adverse weather and poor lighting (e.g. [30, 36, 41, 59]). Most of the above studies use different definitions of severity and do not specifically distinguish seriously injured people in their analyses.

Although the transport policy objective includes reducing both fatalities and serious injuries, traffic safety analysis has until recently focused primarily on fatalities. Consequently, missing knowledge on serious injuries is preventing transport planning and policy from highlighting different aspects and challenges that are not associated with fatalities. The knowledge gap relates to both the characteristics of serious injuries and effective measures to prevent them. The focus on fatalities can be attributed largely to a lack of common definitions for other severities and insufficient accident data that is both reliable and accurate. A particularly frequent challenge across Europe is under-reporting of injury-related accidents [67]. With these challenges in mind, the EU has recommended using the Maximum Abbreviated Injury Scale (MAIS) 3+ criteria for defining a serious injury and recording serious injuries by combining hospital and police data [8]. However, most EU countries do not follow these recommendations [2]; Finland is one of the few that do and has done so since 2014. Despite the potential of this data to broaden our understanding of serious injuries, it has yet to be analysed at road-user level.

Looking at the country's overall traffic safety situation and development, Finland lags behind similar countries in Europe [16]. Overall, six pedestrian fatalities could be prevented annually in Finland if the fatality risk per person kilometre were the same as in Sweden [45]. The Finnish transport policy objective states that the transportation system should be planned in way that no person is killed or seriously injured (KSI) in road traffic, i.e. Vision Zero [19]. In Finland, the European Declaration on Road Safety translates to a maximum of 136 fatalities in 2020 and 68 in 2030. Nonetheless, during the last 5 years 250 people on average have died annually in road traffic in Finland [57]. Another official target is to increase both the number of trips made on foot and by bicycle by $30 \%$ by 2030 , which translates as an increase of 450 million trips on foot or by bicycle [20]. In relation to this resolution, the Ministry of Transport and Communications published a programme with 31 measures to increase walking and cycling in Finland [34]. However, only one of the measures deals specifically with traffic safety; this in spite of the fact presented above that safety is a precondition for walking, and that according to Vision Zero, mobility cannot be traded for safety (e.g. [26, 28, 61]). Therefore, Finland is an important case for gaining detailed knowledge of the characteristics of both fatalities and serious injuries, so that the traffic safety work can be amended and redirected towards achieving all of the country's transport policy objectives.

Given the above, the main objective of this study was to identify the factors associated with pedestrian fatalities and serious injuries in Finland by exploiting official accident data, which since 2014 has included serious injuries reported according to MAIS3+ criteria by combining police and hospital reports. First, the study aimed to describe the overall prevalence of pedestrian fatalities and serious injuries in road traffic in Finland and to compare the rate according to demographic, spatial and temporal variables. Second, the study aimed to explore and describe the factors related to pedestrian fatalities and serious injuries, and to compare whether there are differences between the severities. The methodological focus is on describing aggregated data, as opposed to being a quantitative prediction study or an analysis of in-depth reconstruction results. In line with previous research methodologies, variables included in the analysis were related to pedestrian, driver, vehicle, location, road and weather conditions, and time of occurrence. The results provide information on pedestrian fatalities and serious injuries and allow similarities and differences between the two severities to be identified. The results are 
reflected in traffic safety measures that would better address serious injuries to pedestrians as well as fatalities. The second section of the paper outlines the methodological framework, including data sources and safety performance indicators used. The third section provides a detailed overview of the results on the prevalence of pedestrian fatalities and serious injuries, as well as the associating factors. The fourth section discusses the results, and the fifth and final section concludes the paper.

\section{Methodology}

The data included all police-reported pedestrian fatalities and MAIS3+ serious injuries (linked with hospital data) in Finland during the period 20142017 [57]. The study was limited to road traffic and included all KSI pedestrians involved in accidents with a motor vehicle (i.e. passenger car, van, bus, truck, moped, motorcycle or other motor-driven vehicle). KSI pedestrians involved in accidents with a train $(n=7)$, tram $(n=4)$ or bicycle $(n=9)$ were not included, since these modes have different characteristics (e.g. yielding, speed limit, dedicated infrastructure) than motor vehicles, and the number of observations were too low to include in their own class. Furthermore, only one city in Finland (Helsinki) has trams, and bicycle accidents are heavily underreported (e.g. [55]). The total for the period 2014-2017 was 285 KSI pedestrians in 281 accidents involving 287 drivers and vehicles. Of all the KSI pedestrians, 116 were killed and 169 seriously injured. The paper analyses the number of pedestrian fatalities and serious injuries as opposed to the number of accidents where these occurred.

\subsection{Pedestrian fatality and serious injury rate}

The prevalence of pedestrian fatalities and serious injuries was studied by calculating the pedestrian KSI rate and comparing it according to demographic, spatial and temporal variables. This approach is appropriate when monitoring and comparing the overall traffic safety situation to identify safety-critical issues (e.g. [46]). The pedestrian KSI rate is defined as the number of all fatalities and serious injuries divided by the corresponding exposure. Exposure is derived from the Finnish National Travel Survey of 2016 [18], which includes mobility information (number of trips, distance travelled and mode share) for all mainland residents aged over 6 years. Person-kilometres walked is used as exposure, since it has been acknowledged as a good determinant of pedestrian safety (e.g. [46]), and because the number of short trips is often more underreported than trip length in travel surveys (e.g. [52]). Hence, the pedestrian KSI rate is the average prevalence of a pedestrian being killed or seriously injured by a motor vehicle ${ }^{1}$ per million kilometres walked. It was calculated as follows:

Pedestrian KSI rate $=\frac{\text { Annual average number of KSI pedestrians }}{\text { Annual million kilometres } \text { walked }}$

The mobility data $(\mathrm{km} /$ person/day) is disaggregated and reported in the national travel survey by different variables; the pedestrian KSI rate was compared based on the following: gender, age, type of municipality, area type, season, and day of the week. The categories for gender (male; female) and age (6-17; $18-34 ; 35-54 ; 55-64 ; 65-74 ;+75$ years) were defined in the national travel survey. The categories for type of municipality (metropolitan area; large city; midsized city; small city; small municipality) were defined in the national travel survey and are based on the municipality key (Fig. 1a). The categories for area type (inner urban area; outer urban area; peri-urban area; local centre in rural area; rural area close to urban area; rural heartland area; sparsely populated rural area) were defined in the national travel survey and are based on an official classification by the Finnish Environment Institute, which divides the country into grid squares of $250 \mathrm{~m} \times 250 \mathrm{~m}$ classified according to the type of land use (Fig. 1b). To calculate exposure (annual million kilometres walked) for all the variables' categories, the mobility data from the national travel survey was multiplied by the population size and period length of the corresponding category.

The accident data was recoded based on the categories of the national travel survey: type of municipality by municipality key, and area type according to the coordinates of the accident. To match the data on KSI to the exposure data, KSI involving pedestrians under the age of 6 years $(n=2)$ and occurring on the non-mainland $(n=1)$ were omitted from the KSI rate analysis. As such, the data for calculating pedestrian KSI rate included 282 KSI pedestrians over the age of 6 years, where the other party was a motor vehicle and the accident occurred on the mainland. The results for the pedestrian KSI rate are presented in Section 3.1

\subsection{Factors associated with pedestrian fatalities and serious injuries}

Pedestrian fatalities and serious injuries were analysed according to the following factors: pedestrian, driver,

\footnotetext{
${ }^{1}$ The pedestrian KSI rate was also calculated for all vehicles (motor vehicles, trams and bicycles), but an examination showed that the categories' rates followed the same pattern.
} 


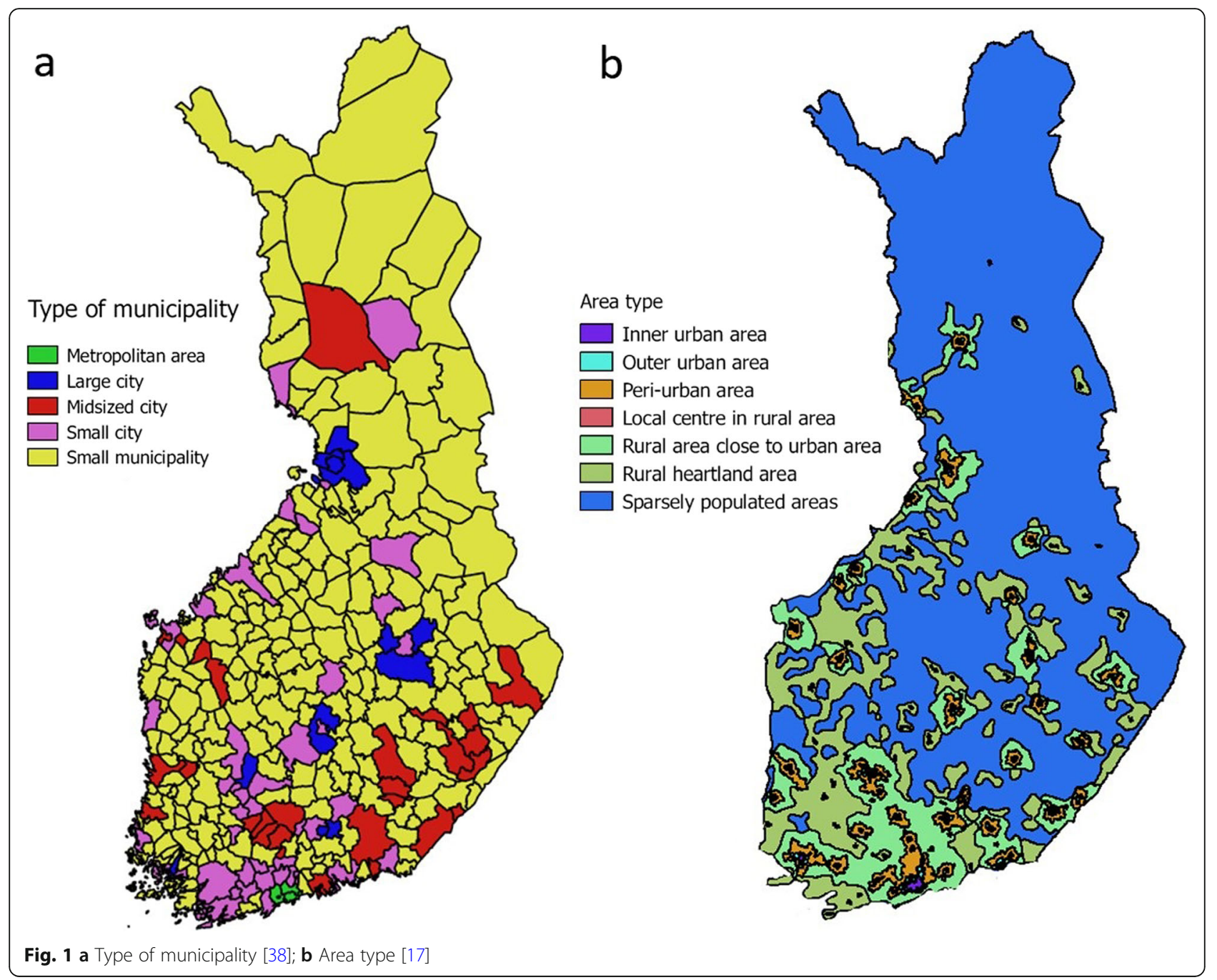

vehicle, accident location, and time of occurrence (excluding missing cases). The main results of the analysis on the factors associated with pedestrian fatalities and serious injuries are presented in frequency tables. The results were analysed with a Chi-Square test of independence [54] to identify statistically significant differences between the factors associated with pedestrian fatalities and serious injuries. The test compares the expected frequency in the cells of a contingency table with the observed frequencies. The same methodology has been applied in previous studies (e.g. [56]). Where available statistics were found, the differences in severities were compared relative to the dimensions of the category sizes by first calculating the relative shares (number of observations relative to the size of the category) and then comparing the relative ratio (relative share of all categories relative to the relative share of the first category of the variable) between categories. This was done for pedestrian gender and age group [18], driver gender and age group [63], and vehicle type [64]. After the relevant variables were identified, their relative contribution was evaluated (in SPSS) using binomial regression models. Thus, the main purpose of the analysis is to identify whether there are differences in where the main challenges lie for pedestrian fatalities and serious injuries.

The accident statistics also included other variables, such as pedestrian and driver intoxication, but these are excluded from the analysis due to missing data. Some categories were combined due to a low number of observations. The included variables, original and final categories and number of missing cases are presented in Appendix 1. Looking at the correlation between variables presented in Appendix 3, the only strong correlation, the Pearson correlation coefficient $r>0.07$, ([54], p. 777) was between municipality and 
area type. The results for the factors associated with pedestrian fatalities and serious injuries are presented in Section 3.2. Finally, we underline that there are no control datasets for the variables considered in this study.

\section{Results}

\subsection{Pedestrian fatality and serious injury rate}

\subsubsection{Pedestrian characteristics}

The number of pedestrian fatalities and serious injuries per million kilometres walked according to gender and age is presented in Fig. 2. The rate was higher (approx. 40\%) for males than females. The rate was over five times higher for those aged 75 years or above compared to the other age groups (19.6 vs. 2.1-3.7). The rate for the other age groups were also lower than the total rate. When comparing the age groups by gender, the rate for males was almost twofold that for the age groups 18-34 and 55-64 years and fourfold for the age group 35-54 years compared to females. For the older age groups (65-74 and over 75 years), the rate was higher (approx. 10\%) for females than males.

\subsubsection{Location}

The number of pedestrian fatalities and serious injuries per million kilometres walked according to type of municipality and area type is presented in Fig. 3. Compared to the overall pedestrian KSI rate, the rate was higher in small municipalities (50\%), midsized cities (35\%), and small cities (8\%). The corresponding rate was lower (approx. 15-30\%) in both the metropolitan area and large cities; in the metropolitan area the pedestrian KSI rate was almost half that in small municipalities and midsized cities. Compared to the overall pedestrian KSI rate, the rate was higher in rural heartland areas (approx. $220 \%$ ), local centres in rural areas (approx. 50\%), and in inner urban areas (approx. 5\%). The corresponding rate was lower (approx. 25\%) in outer urban areas, rural areas close to urban areas, and sparsely populated areas. The rate was over twofold for rural heartland areas (8.3) compared to all other area types (3.0-4.0), except for local centres in rural areas where it was $60 \%$ higher.

\subsubsection{Time of occurrence}

The number of pedestrian fatalities or serious injuries per million kilometres walked according to season and day of the week is presented in Fig. 4. Compared to the overall pedestrian KSI rate, the rate was higher (approx. 25-35\%) in autumn and winter and lower (approx. 20$25 \%)$ in spring and summer. Compared to the overall pedestrian KSI rate, the rate was higher (approx. 2025\%) on Tuesdays, Thursdays and Fridays and lower (approx. 45\%) on Sundays. For the other days, the rate was similar to the overall rate.

\subsection{Factors associated with pedestrian fatalities and serious injuries \\ 3.2.1 Pedestrian characteristics}

There were no statistically significant differences between the pedestrian's injury severity and gender or

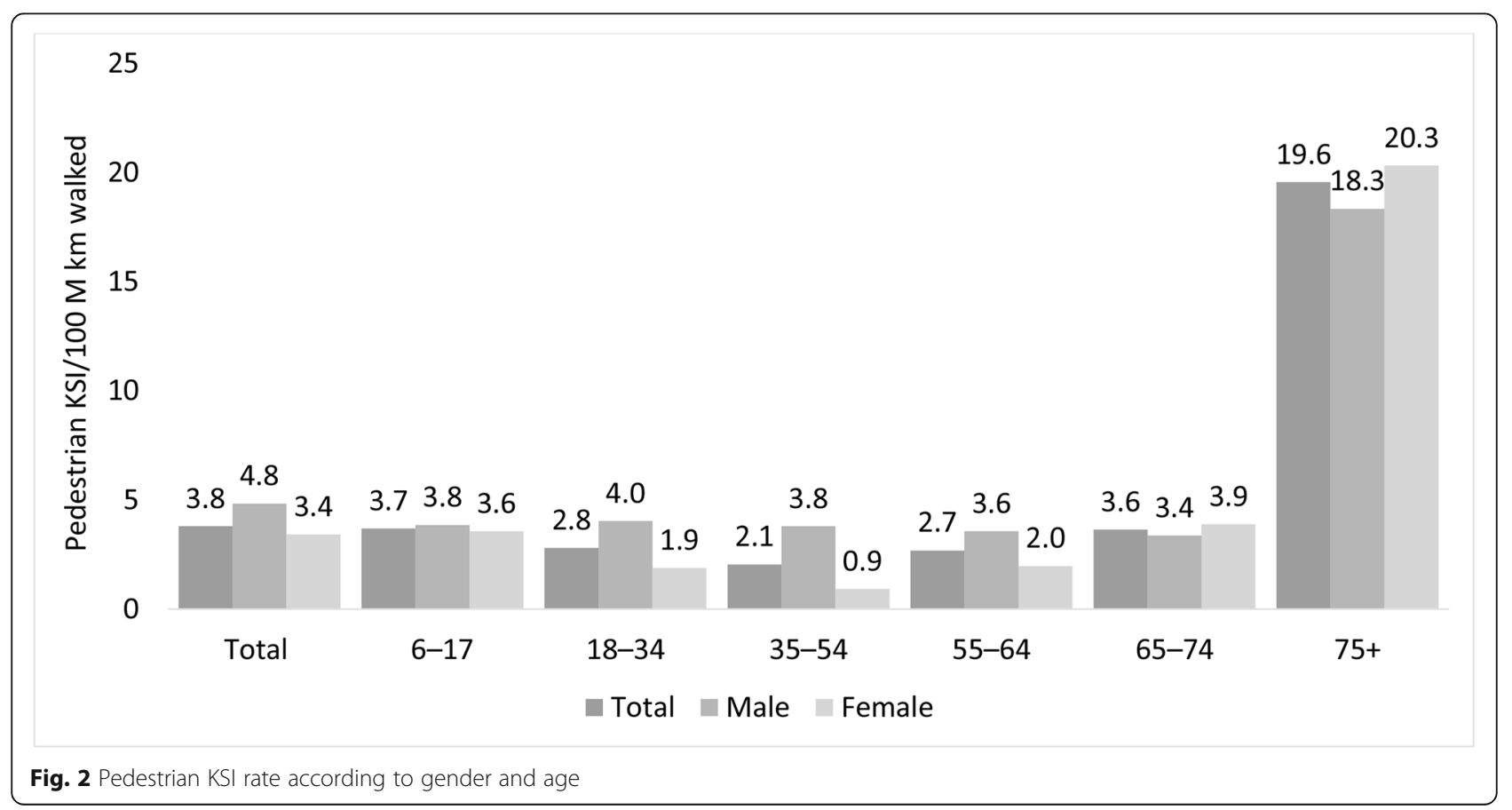




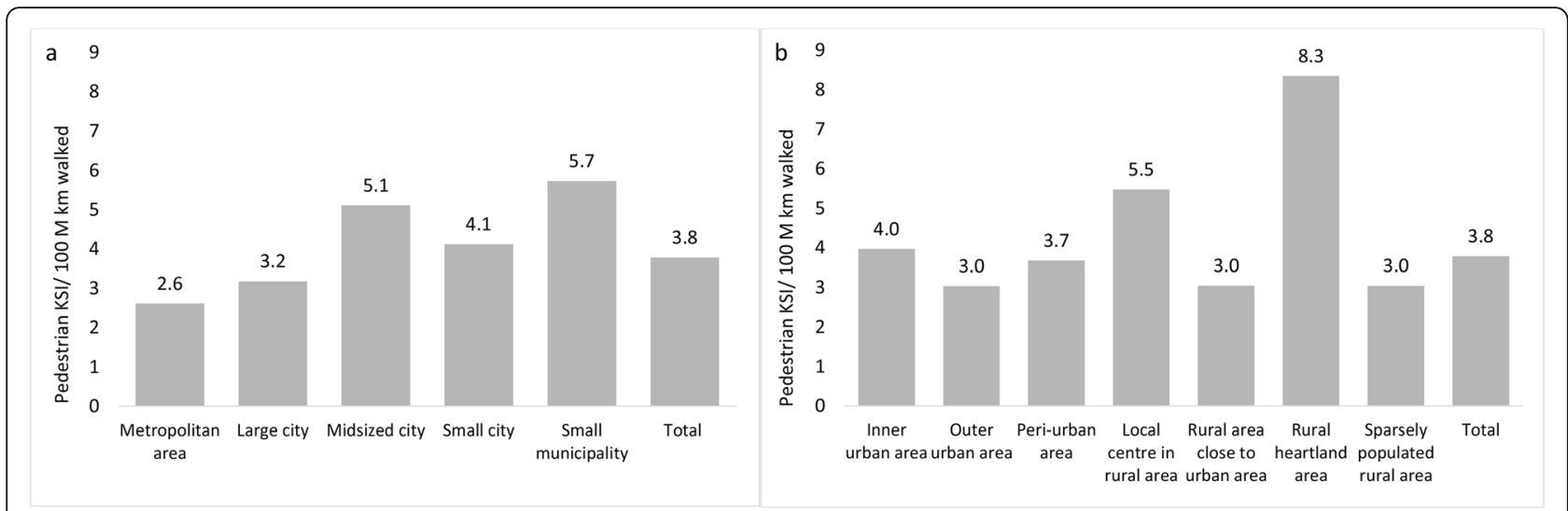

Fig. 3 Pedestrian KSI rate according to (a) type of municipality and (b) area type

age $(n=285)$. A majority of deceased pedestrians were male $(53 \%)$ and of seriously injured pedestrians female $(53 \%)$. In terms of age groups, $32 \%$ were aged over 75 years and the share for the other age groups $(0-17 ; 18-34 ; 35-54 ; 55-64)$ was $11-16 \%$. When comparing observations relative to gender and age group sizes (Appendix 2), the relative ratio was over fourfold for age over 75 years compared to age 0-17 years. The difference in relative ratio was small (0.41.7) for the other age groups compared to 0-17-year olds and for women compared to men (relative ratio $0.8-1.1)$.

\subsubsection{Driver characteristics}

There were no statistically significant differences between injury severity and the driver's gender $(n=$ $281)$, age $(n=277)$ or driving licence age $(n=236)$. A majority $(72 \%)$ of the involved drivers were male. Of all the involved drivers, 33\% were aged 15-34, 31\% were aged 35-54, 20\% were aged 55-64, and 8\% were aged 65-74 and over 75 years respectively. When comparing observations relative to the gender and age group sizes (Appendix 2), there was no major differences between groups (relative ratio varied between 0.4 and 1.4). The age of their driving licence was more than 5 years for around $70 \%$ of the drivers and less than 1 year and between 1 and 5 years for around $15 \%$ of the drivers, respectively.

\subsubsection{Vehicle characteristics}

Table 1 shows the vehicle type classification according to fatality or serious injury, including absolute (comparing observations in the categories) and relative (comparing observations relative to the dimensions of the categories) shares as well as relative ratio (comparing relative shares of other vehicle types to

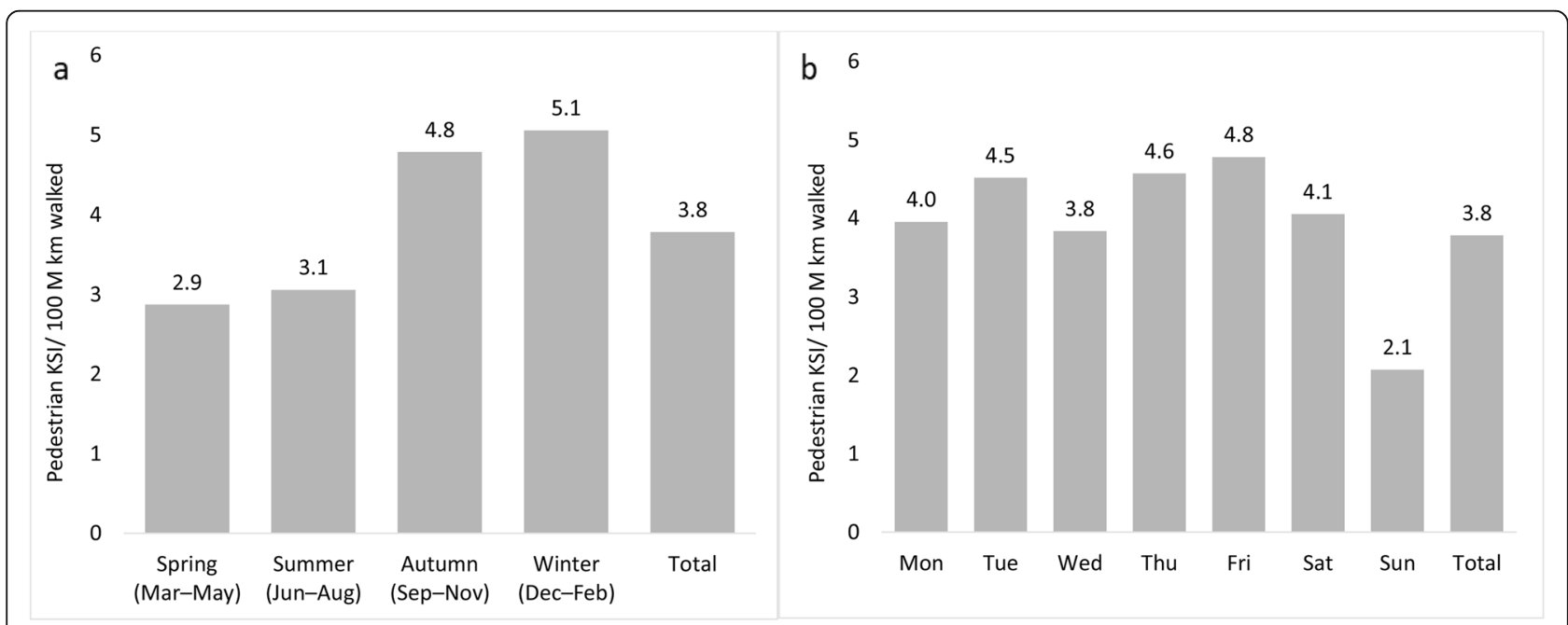

Fig. 4 Pedestrian $\mathrm{KSI}$ rate according to (a) season and (b) day of the week 
Table 1 Involved vehicle type ( $n=287)$ according to pedestrian fatality and serious injury

\begin{tabular}{|c|c|c|c|c|c|c|c|c|c|c|c|c|c|}
\hline & \multirow[b]{2}{*}{ Size } & \multicolumn{4}{|c|}{ Fatality } & \multicolumn{4}{|c|}{ Serious injury } & \multicolumn{4}{|c|}{ Total } \\
\hline & & $n$ & Abs \% & Rel \% & Relative ratio & $n$ & Abs $\%$ & Rel \% & Relative ratio & $n$ & Abs \% & Rel \% & Relative ratio \\
\hline $\begin{array}{l}\text { Passenger } \\
\text { car }\end{array}$ & $2,696,334$ & 59 & 51 & 0.00002 & 1.0 & 125 & 73 & 0.00005 & 1.0 & 184 & 64 & 0.00007 & 1.0 \\
\hline Van & 325,656 & 15 & 13 & 0.00005 & 2.1 & 10 & 6 & 0.00003 & 0.7 & 25 & 9 & 0.00008 & 1.1 \\
\hline Bus & 12,481 & 8 & 7 & 0.00064 & 29.3 & 13 & 8 & 0.00104 & 22.5 & 21 & 7 & 0.00168 & 24.7 \\
\hline Truck & 96,169 & 24 & 21 & 0.00025 & 11.4 & 13 & 8 & 0.00014 & 2.9 & 37 & 13 & 0.00038 & 5.6 \\
\hline Other & $1,906,590$ & 10 & 8 & 0.00001 & 0.2 & 10 & 6 & 0.00001 & 0.1 & 20 & 7 & 0.00001 & 0.2 \\
\hline Total & $5,037,230$ & 116 & 100 & & & 171 & 100 & & & 287 & 100 & & \\
\hline
\end{tabular}

that with passenger car). A majority (64\%) of all KSI pedestrian incidents involved a passenger car (Table 1). Pedestrian serious injuries more often involved a passenger car than did pedestrian fatalities $(73 \%$ vs. $51 \%)$, whereas pedestrian fatalities more often involved a truck than did serious injuries (21\% vs. $8 \%)$ $\left(x^{2}(1)=19.304, p<0.001\right)$. Compared to passenger cars, the relative ratio was over twentyfold for buses for both severities, and over eleven times higher for trucks for fatalities. There was no statistically significant difference between injury severity and vehicle age $(n=271)$; in $48 \%$ of the incidents the vehicle was over 5 years old and in $26 \%$ of the incidents less than 1 year old and between 1 and 5 years old, respectively.

Table 2 Speed limit $(n=285)$, location $(n=285)$, municipality type $(n=284)$, and area type $(n=285)$ according to pedestrian fatality and serious injury

\begin{tabular}{|c|c|c|c|c|c|c|c|}
\hline & & \multicolumn{2}{|c|}{ Fatality } & \multicolumn{2}{|c|}{ Serious injury } & \multicolumn{2}{|c|}{ Total } \\
\hline & & $\mathrm{n}$ & $\%$ & $\mathrm{n}$ & $\%$ & $n$ & $\%$ \\
\hline \multirow[t]{5}{*}{ Speed limit } & $\leq 30 \mathrm{~km} / \mathrm{h}$ & 10 & 9 & 16 & 9 & 26 & 9 \\
\hline & $40 \mathrm{~km} / \mathrm{h}$ & 41 & 35 & 83 & 49 & 124 & 43 \\
\hline & $50-70 \mathrm{~km} / \mathrm{h}$ & 26 & 22 & 59 & 35 & 85 & 30 \\
\hline & $\geq 80 \mathrm{~km} / \mathrm{h}$ & 39 & 34 & 11 & 7 & 50 & 18 \\
\hline & Total & 116 & 100 & 169 & 100 & 285 & 100 \\
\hline \multirow[t]{5}{*}{ Place of accident } & Carriageway & 60 & 52 & 58 & 34 & 118 & 41 \\
\hline & Pedestrian crossing & 31 & 27 & 83 & 49 & 114 & 40 \\
\hline & Car park & 18 & 15 & 18 & 11 & 36 & 13 \\
\hline & Other (cycle path, bridge, bus stop) & 7 & 6 & 10 & 6 & 17 & 6 \\
\hline & Total & 116 & 100 & 169 & 100 & 285 & 100 \\
\hline \multirow[t]{6}{*}{ Municipality type } & Metropolitan area & 16 & 14 & 29 & 17 & 45 & 16 \\
\hline & Large city & 16 & 14 & 35 & 21 & 51 & 18 \\
\hline & Midsized city & 19 & 17 & 41 & 24 & 60 & 21 \\
\hline & Small city & 19 & 17 & 37 & 22 & 56 & 20 \\
\hline & Small municipality & 45 & 39 & 27 & 16 & 72 & 25 \\
\hline & Total & 115 & 100 & 169 & 100 & 284 & 100 \\
\hline \multirow[t]{6}{*}{ Area type } & Inner urban area & 29 & 25 & 86 & 51 & 115 & 40 \\
\hline & Outer urban area & 23 & 20 & 38 & 22 & 61 & 21 \\
\hline & Peri-urban area and rural area close to urban area & 20 & 17 & 13 & 8 & 33 & 12 \\
\hline & Local centre in rural area & 15 & 13 & 10 & 6 & 25 & 9 \\
\hline & Sparsely populated rural and rural heartland area & 29 & 25 & 22 & 13 & 51 & 18 \\
\hline & Total & 116 & 100 & 169 & 100 & 285 & 100 \\
\hline
\end{tabular}




\subsubsection{Location characteristics}

Most (43\%) of the KSI pedestrians were in speed limit zones of $40 \mathrm{~km} / \mathrm{h}$ (Table 2). Pedestrian fatalities occurred more often in zones over $80 \mathrm{~km} / \mathrm{h}$ than did serious injuries (34\% vs. $7 \%)$, whereas fatalities occurred less often in $40 \mathrm{~km} / \mathrm{h}(35 \%$ vs. $49 \%)$ and $50-70 \mathrm{~km} / \mathrm{h}(22 \%$ vs. $35 \%)$ zones than did serious injuries $\left(x^{2}(1)=35.473, p<0.000\right)$. Looking at the place of occurrence, around $40 \%$ of all KSI pedestrians were in incidents on carriageways and pedestrian crossings respectively. Comparing the place of occurrence based on pedestrian injury severity, fatalities occurred more often on a carriageway than did serious injuries ( $52 \%$ vs. $34 \%$ ), whereas fatalities occurred less often on pedestrian crossings than did serious injuries $(27 \%$ vs. $49 \%)\left(x^{2}(1)=14.943, p<0.002\right)$. Among all KSI pedestrians, $25 \%$ of the incidents occurred in small municipalities, $20-21 \%$ in midsized and small cities, and $16-18 \%$ in the metropolitan area and large cities. Pedestrian fatalities occurred more often in small municipalities than did serious injuries (39\% vs. 16\%), whereas serious injuries occurred more often in all other municipality types than did fatalities $\left(x^{2}(1)=19.628, p<0.001\right)$. Looking at the area type, $40 \%$ of all KSI pedestrians were in inner urban areas. Pedestrian serious injuries occurred more often in inner urban areas than did fatalities (51\% vs. 26\%), whereas fatalities occurred more often in sparsely populated rural and rural heartland areas than did serious injuries $(25 \%$ vs. $13 \%)\left(x^{2}(1)=31.682, p<\right.$ $0.000)$. There was a strong correlation $(\mathrm{r}=0.751)$ between municipality and area type (Appendix 3). Comparing municipality type with area type for all KSI pedestrians, it was found that a majority of metropolitan areas, large cities and midsized cities are inner urban areas (50-89\%), whereas a majority of small municipalities are sparsely populated rural and rural heartland areas (60\%). Further comparisons revealed that the road operator was the Finnish Transport Infrastructure Agency (FTIA) in a majority of fatalities in all municipality types (53-60\%) except in metropolitan areas and large cities, where the road operator in most cases was the municipality (44-75\%). This is in contrast to serious injuries where the municipality was the main road operator for all municipality types (78-86\%), except for small municipalities where the share was somewhat lower $(48 \%)$.

\subsubsection{Road and weather condition characteristics}

Of all KSI pedestrians, $48 \%$ were in dry road conditions (Table 3). Pedestrian fatalities occurred less often in wet road conditions than did serious injuries (21\% vs. $37 \%)$, whereas fatalities occurred more often than serious injuries in dry road conditions (55\% vs. $44 \%)$ and winter road conditions $(24 \%$ vs. $20 \%)\left(x^{2}(1)=7.216 p<0.027\right)$. A majority $(59 \%)$ of all pedestrian fatalities and serious injuries occurred in daylight. Pedestrian fatalities occurred less often in places with streetlights lit than did serious injuries (13\% vs. $31 \%)$, whereas fatalities occurred more often in daylight than did serious injuries $(66 \%$ vs. $53 \%)\left(x^{2}(1)=13.649, p<0.003\right)$. A majority $(54 \%)$ of all KSI pedestrians were in temperature conditions above $3{ }^{\circ} \mathrm{C}$. Pedestrian fatalities occurred less often in temperature conditions of $-3-3{ }^{\circ} \mathrm{C}$ than did serious injuries $(28 \%$ vs. $40 \%)$, whereas fatalities occurred more often at temperatures below $-3{ }^{\circ} \mathrm{C}$ than did serious

Table 3 Road surface $(n=271)$, lighting conditions $(n=285)$, temperature $(n=285)$ and weather conditions $(n=275)$ according to pedestrian fatality and serious injury

\begin{tabular}{|c|c|c|c|c|c|c|c|}
\hline & & \multicolumn{2}{|c|}{ Fatality } & \multicolumn{2}{|c|}{ Serious injury } & \multicolumn{2}{|c|}{ Total } \\
\hline & & $n$ & $\%$ & $\mathrm{n}$ & $\%$ & $n$ & $\%$ \\
\hline \multirow[t]{4}{*}{ Road surface } & Dry & 56 & 55 & 73 & 43 & 129 & 48 \\
\hline & Wet & 22 & 21 & 62 & 37 & 84 & 31 \\
\hline & Winter conditions & 25 & 24 & 33 & 20 & 58 & 21 \\
\hline & Total & 103 & 100 & 168 & 100 & 271 & 100 \\
\hline \multirow[t]{5}{*}{ Lighting conditions } & Daylight & 77 & 66 & 90 & 53 & 167 & 59 \\
\hline & Dawn or twilight & 6 & 5 & 11 & 7 & 17 & 6 \\
\hline & No streetlights or streetlights unlit & 18 & 16 & 16 & 9 & 34 & 12 \\
\hline & Streetlights lit & 15 & 13 & 52 & 31 & 67 & 23 \\
\hline & Total & 116 & 100 & 169 & 100 & 285 & 100 \\
\hline \multirow[t]{4}{*}{ Temperature } & $<-3{ }^{\circ} \mathrm{C}$ & 18 & 16 & 12 & 7 & 30 & 11 \\
\hline & $-3-3^{\circ} \mathrm{C}$ & 33 & 28 & 68 & 40 & 101 & 35 \\
\hline & $>3^{\circ} \mathrm{C}$ & 65 & 56 & 89 & 53 & 154 & 54 \\
\hline & Total & 116 & 100 & 169 & 100 & 285 & 100 \\
\hline
\end{tabular}


injuries $(16 \%$ vs. $7 \%)\left(x^{2}(1)=7.471, p<0.024\right)$. There was no statistically significant difference between injury severity and weather conditions. Among all pedestrian KSI, $42 \%$ were in cloudy and clear weather conditions respectively and $16 \%$ were in other weather conditions (fog, rain, snow or sleet).

\subsubsection{Time of occurrence characteristics}

There were no statistically significant differences between injury severity and season, day of the week or time of day $(n=285)$. Of all pedestrian fatalities and serious injuries, 33\% occurred in winter (Dec-Feb), $32 \%$ in autumn (Sep-Nov), 19\% in spring (Mar-May) and $16 \%$ in summer (Jun-Aug). Regarding the day of the week, $14-17 \%$ of all pedestrian KSI incidents occurred on weekdays and $8-14 \%$ at weekends. Looking at the corresponding time of day, $40 \%$ occurred in the afternoon (12:00-17:59), 33\% in the morning (6: $00-11: 59), 16 \%$ in the evening (18:00-23:59) and $10 \%$ at night (00:00-5:59).

\subsubsection{Differences in pedestrian fatalities and serious injuries and relative contribution of identified variables}

The main differences between pedestrian fatalities and serious injuries related to vehicle type, municipality type, area type, accident location, current speed limit, temperature, and road and lighting conditions. No differences were found for factors related to pedestrian and driver characteristics, vehicle age, weather conditions, or time of occurrence. To determine the most relevant variables for explaining the difference between severities, a binary logistic regression analysis was carried out where the dependent variable was injury severity. Since a strong correlation was identified between municipality type and area type $(r=0.751)$ (Appendix 3$)$, two separate models where first developed, one with municipality type and the other with area type. The variables (model 1: vehicle type, municipality type, accident location, current speed limit and road and lighting conditions; model 2: vehicle type, area type, accident location, current speed limit and road and lighting conditions) were inserted stepwise into the model and were selected when the $p$ value for the Wald statistics was significant $(p<.05)$. The model was based on 271 of the 285 KSI pedestrians, as data was missing on road condition. Model 1 explains more of the variance compared to model 2 (Nagelkerke $R^{2}: 26.8 \%$ vs. $22.7 \%$ ); thus, we henceforth concentrate on that model. According to the results, speed limit, lighting conditions and municipality type are the statistically significant variables. Looking at the individual variables of the variance (comparing Nagelkerke $R^{2}$ between the three stepwise models), speed limits account for $15.7 \%$, lighting conditions for $7 \%$, and municipality type for $4.1 \%$ of the variance. The final logistic regression model was statistically significant $\left(X^{2}(10)=59.114\right.$, $p<0.001)$ and the model correctly classified $72.2 \%$ of the cases. Table 4 presents the results from the final model and shows that there is a highly significant overall effect of speed limits (Wald $=26.019, d f=3$, $p<0.001$ ), lighting conditions (Wald $=11.688, d f=3$, $p<0.009$ ), and municipality type (Wald $=9.738, d f=4$, $p<0.045)$. According to the results, the odds for fatality increase significantly for the speed limit zone $\geq 80 \mathrm{~km} / \mathrm{h}$ $(O R=7.901, p<.001)$ compared to $\leq 30 \mathrm{~km} / \mathrm{h}$. The odds

Table 4 Significant variables and related estimates and odds ratios for binary logistic model

\begin{tabular}{|c|c|c|c|c|c|}
\hline & $\begin{array}{l}\text { Regression coefficient } \\
\text { (std. error) }\end{array}$ & Wald & $d f$ & Sig. & OR $[95 \% \mathrm{Cl}]$ \\
\hline Constant & $0.338(0.521)$ & 0.423 & 1 & 0.516 & 1.403 \\
\hline$\leq 30 \mathrm{~km} / \mathrm{h}$ & & 26.019 & 3 & 0.000 & \\
\hline $40 \mathrm{~km} / \mathrm{h}$ & $-0.183(0.491)$ & 0.138 & 1 & 0.710 & $0.833[0.318,2.182]$ \\
\hline $50-70 \mathrm{~km} / \mathrm{h}$ & $-0.086(0.527)$ & 0.027 & 1 & 0.870 & $0.917[0.327,2.578]$ \\
\hline$\geq 80 \mathrm{~km} / \mathrm{h}$ & $2.067(0.621)$ & 11.086 & 1 & 0.001 & $7.901[2.340,26.674]$ \\
\hline Daylight & & 11.688 & 3 & 0.009 & \\
\hline Dawn or twilight & $-0.709(0.613)$ & 1.337 & 1 & 0.248 & $0.492[0.148,1.636]$ \\
\hline No streetlights or streetlights unlit & $-0.589(0.496)$ & 1.411 & 1 & 0.235 & $0.555(0.210,1.466]$ \\
\hline Streetlights lit & $-1.366(0.407)$ & 11.292 & 1 & 0.001 & $0.255(0.115,0.566]$ \\
\hline Small municipality & & 9.738 & 4 & 0.045 & \\
\hline Small city & $-0.580(0.441)$ & 1.730 & 1 & 0.188 & $0.560[0.236,1.329]$ \\
\hline Midsized city & $-1.127(0.459)$ & 6.029 & 1 & 0.014 & $0.324[0.132,0.797]$ \\
\hline Large city & $-1.090(0.422)$ & 6.671 & 1 & 0.010 & $0.336[0.148,0.769]$ \\
\hline Metropolitan area & $-0.907(0.422)$ & 4.625 & 1 & 0.032 & $0.404[0.177,0.923]$ \\
\hline
\end{tabular}


for fatality decrease significantly for streetlights lit compared to daylight $(O R=0.255, p<0.001)$. Compared to small municipality, the odds for fatality decreases significantly for a mid-sized city $(O R=0.324, p<0.014)$, large city $(O R=0.336, p<0.010)$ and metropolitan area $(O R=0.404, p<0.032)$. No statistical differences were found between $\leq 30 \mathrm{~km} / \mathrm{h}$ and $40 \mathrm{~km} / \mathrm{h}$ or 50 $70 \mathrm{~km} / \mathrm{h}$ between daylight and dawn or twilight or no streetlights or streetlights unlit, or between small municipality and small city.

\section{Discussion}

\subsection{General implications}

The main results of the study showed that the overall prevalence of pedestrians being killed or seriously injured by a motor vehicle was 3.8 per 100 million kilometres walked. The results also showed that the rate was higher for males than females. When comparing age groups, the rate was higher for men than for women in all age groups, except for elderly pedestrians (aged over 65 years), where the rate was higher for women than for men, and for young pedestrians (6-17), where the rate was of similar magnitude. When comparing all age groups, the rate was five times higher for elderly pedestrians than for other age groups. These findings are in line with previous results (e.g. [5, 14, 27, 29, 30, 45, 59]). Compared to the overall pedestrian KSI rate, the rate was higher in mid-sized cities and small municipalities, and lower in the metropolitan area and large cities. In particular, the pedestrian KSI rate was more than double for mid-sized cities and small municipalities compared to the metropolitan area. When comparing the KSI rate by type of area, rural heartland areas stand out as common places for pedestrians to get killed or seriously injured.

When comparing the factors related to KSI pedestrians based on severity, differences were found for vehicle type, municipality type, area type, accident location, current speed limit, temperature, and road and lighting conditions. Looking at the combined effect on severity of all independently significant variables, the most relevant variable was speed limit, followed by lighting conditions and municipality type. Around half of all KSI pedestrians were in speed limit zones up to $40 \mathrm{~km} / \mathrm{h}$. When comparing severities, pedestrian fatalities occurred more often in speed limit zones over $80 \mathrm{~km} / \mathrm{h}$ than did serious injuries (34\% vs. $7 \%$ ). Similar results have been found for other countries (e.g. [14, 29] p. $16 \& 81$ [58];). On the other hand, serious injuries to pedestrians occurred more often than fatalities in speed limit zones of $40 \mathrm{~km} / \mathrm{h}(35 \%$ vs. $49 \%)$ or $50-70 \mathrm{~km} / \mathrm{h}$ (22\% vs. $35 \%)$. These are considerably larger differences than in Sweden, where of all motor vehicle-pedestrian KSI accidents, only $6-11 \%$ occurred in speed limit zones of $40 \mathrm{~km} / \mathrm{h}$, and $60-66 \%$ in $50-70 \mathrm{~km} / \mathrm{h}$ speed limit zones ([29] p. 16). This may relate to the fact that the default speed limit on rural roads is $70 \mathrm{~km} / \mathrm{h}$ in Sweden but $80 \mathrm{~km} / \mathrm{h}$ in Finland. Previous research has strongly linked pedestrian injury severity and vehicle speed to a rapidly increasing fatality risk when speeds exceed 52 $\mathrm{km} / \mathrm{h}$ for passenger cars and $39 \mathrm{~km} / \mathrm{h}$ for heavier vehicles $[49,60]$. Looking at lighting conditions, pedestrian fatalities occurred more often than serious injuries in daylight, whereas serious injuries occurred more often than fatalities with streetlights lit. Previous research has found a higher risk for fatality than other severities for both darkness (e.g. [30, 36, 59]) and daylight (e.g. [58]) compared to other lighting conditions. The share of all pedestrian fatalities and serious injuries was similar by municipality type. However, when comparing them based on severity, fatalities occurred more often in small municipalities than did serious injuries (39\% vs. 16\%), whereas serious injuries occurred more often in all other municipality types than did fatalities. Municipality type had a strong correlation with area type (Appendix 3). Looking at area type, a majority (61\%) of all pedestrian fatalities and serious injuries occurred in inner and outer urban areas. When comparing severity, serious injuries to pedestrians were more common than fatalities in inner urban areas (51\% vs. $25 \%$ ) but less common in sparsely populated rural and rural heartland areas (13\% vs. $25 \%$ ). Comparing municipality type and road operator, it was found that for fatalities the main road operator was the FTIA for all municipality types except metropolitan area and large cities, whereas for serious injuries the main road operator was the municipality for all municipality types except small municipality. Similarly, previous research has found an increase in pedestrian accident severity for villages and sparsely populated areas compared to other areas (e.g. [1, 22, $24,30,37,59,68])$. These findings could relate to the safety-in-numbers phenomenon, i.e. a disproportional increase in the number of pedestrian and cyclist accidents to an increase in the number of pedestrians and cyclists in an area (e.g., [12]), or to an overall safer street environment or lower vehicle speeds thanks to various engineering measures and/ or enforcement (e.g., [48]). For comparison, the share of walking and biking of all travelling was $6 \%$ in the metropolitan area and large cities, but $3-4 \%$ in midsized and small cities and small municipalities [18]. These findings indicate a need for tailored pedestrian traffic safety work for different areas, with special emphasis on rural heartland areas and small municipalities.

Vehicle type, accident location, temperature and road conditions also independently revealed a statistically significant difference between severities. Serious injuries to 
pedestrians more often involved a passenger car than did pedestrian fatalities, whereas pedestrian fatalities more often involved a truck than did serious injuries. This finding is in line with previous research, which has found that pedestrian injury severity is higher for accidents with heavier vehicles (e.g. [5, 30, 50]). A related issue is that suicides are included in the official accident statistics in Finland. According to an in-depth investigation, $7 \%$ of all 748 pedestrian and cyclist fatalities in 2000-2009 were suicides, the other party in most of these cases being a heavy goods vehicle [47]. However, no similar data is yet available for serious injuries, although the Finnish Crash Data Institute is currently developing tools and methodologies for covering these in their in-depth investigations [51]. Confirmed suicides are removed from the official road accident statistics in all of the other Nordic countries. As such, there is a need for common practices for handling and registering suicides and their attempts among European member states.

Looking at the location, pedestrian fatalities occurred more often than serious injuries on carriageways (52\% vs. $34 \%$ ), whereas serious injuries occurred more often than fatalities on pedestrian crossings (49\% vs. $27 \%$ ). These results are in line with previous research, although the shares are slightly smaller than in other countries, where the corresponding shares e.g. in Israel were 65\% vs. $59 \%$ and $41 \%$ vs $35 \%$, and in the US $68 \%$ vs. $62 \%$ and $21 \%$ vs. $19 \%[5,23]$. These differences may relate to the characteristics of the traffic environment and mobility behaviour in each country, and to the fact that the studies from the US and Israel included all injuries and not specifically serious injuries. These results are in line with those on speed limits and area type, since carriageways commonly have higher speed limits and are more often located outside urban areas. As for the road conditions, serious injuries to pedestrians occurred more often on wet roads than did fatalities, whereas fatalities occurred more often than serious injuries on dry roads and in winter road conditions. This is in line with the next finding that pedestrian fatalities occurred more often in temperatures below $-3^{\circ} \mathrm{C}$ than did serious injuries. On the other hand, fatalities occurred less often than serious injuries in temperatures of -3$3{ }^{\circ} \mathrm{C}$, when roads tend to be more slippery. These findings are reflected by earlier research, which has found that injury severity increases in adverse weather conditions (e.g. [30, 41, 59]).

There were no differences in pedestrian or driver characteristics, time of occurrence (season, day of the week and time of day) and weather conditions between pedestrian fatalities and serious injuries. For all the KSI pedestrians, the gender ratio was even, and a third of them were over 75 years old. The majority of drivers were male, and most had had a driving licence for more than 5 years. Looking at the driver's age, around one third were aged 15-34 and 35-54 years, respectively. Furthermore, $42 \%$ of pedestrian KSI incidents occurred in clear and cloudy weather respectively, and $16 \%$ in other conditions such as fog, rain, snow or sleet. Regarding time of year, most pedestrian KSI incidents happened in winter (33\%) and autumn (32\%). Finally, looking at time of day, most pedestrian KSI incidents occurred in the afternoon (40\%) and morning (34\%).

\subsection{Implications for Finland}

When choosing and implementing traffic safety measures, emphasis should be on deploying solutions with a substantial safety potential, i.e. measures that target many accidents. Until recently, traffic safety work focused primarily on fatalities; now, with increased knowledge on serious injuries, it should be amended to cover both severities. For both severities, speed limit reductions can be seen as one of the most promising traffic safety measures. In accordance with the Vision Zero approach, it is recommended to implement $30 \mathrm{~km} / \mathrm{h}$ speed limits on roads where road users are mixed, such as in urban areas. Although some municipalities have recently started implementing them, $30 \mathrm{~km} / \mathrm{h}$ speed limit zones are still quite rare in Finland. For roads with speed limits of up to $50 \mathrm{~km} / \mathrm{h}$, it is recommended to build some kind of physical separation between road users, lower the speed limit to $30 \mathrm{~km} / \mathrm{h}$ at crossing facilities, and, wherever needed, build physical obstacles (fences etc.) to prevent pedestrians from bypassing crossing facilities. For higher speeds, it is recommended to build a dedicated space for pedestrians (and cyclists) with grade separation for any crossing facilities. Since Finland is sparsely populated with a road network consisting largely of rural roads, highrisk locations, such as sections where walking and cycling are common and close to urban areas should be identified and prioritised. In addition to speed limit reductions, measures targeting speed limit compliance (e.g. enforcement, driver assistance systems and physical measures) are relevant for both severities. Looking at fatalities, additional measures to emphasise are physical separation of road users in high-speed zones and blind-spot monitoring and/or automatic emergency braking, especially for heavy goods vehicles. Furthermore, it can be recommended that suicides are removed from official statistics, since they are intentional acts that cannot similarly be prevented through traffic safety measures. That said, enhanced public education and awareness campaigns are needed to prevent suicide and should be 
combined with effective identification and treatment of mental health problems in public health care [43]. Looking at serious injuries, additional measures to emphasise are improvement of pedestrian crossing facilities (e.g. pedestrian islands, raised crossings, curb extensions and signal control) and replacing three- and four-way junctions with roundabouts where appropriate.

The exposure data was collected from the national travel survey, which is based on reported behaviour and does not necessarily reflect actual mobility behaviour. Underreporting is also common in travel surveys, although it is more common for the number of short trips compared to length of trips [52], which is why the latter variable was chosen. All in all, the representativeness of the walking data in the national travel survey was estimated to be good [18], and the comprehensive data enabled the analysis to account for both population size and mobility behaviour. Accident data also poses some uncertainties due to potential underreporting. In Finland, the official statistics include all fatal road traffic accidents involving a motor vehicle. Since 2014, the statistics have also differentiated serious injuries, which has offered a unique opportunity to gain insight into their characteristics. However, traffic accidents with seriously injured pedestrians are still underreported in Finland [44]. Pedestrian single accidents represent a large part of pedestrians' injury accidents but are currently not included in the official road accident statistics. Data collection procedures for both accidents and travel behaviour should be further improved so that decision-making in relation to traffic safety is not distorted by incomplete data.

Including serious injuries in traffic safety work shifts more of the responsibility to municipalities. Nevertheless, the national road operator FTIA should also prioritise pedestrian safety in their activities, since the prevalence of pedestrian fatalities and serious injuries was especially high in rural heartland areas where they are the road operator. Traffic safety measures should be tailored to local conditions, since traffic environments and travel behaviour generally differ depending on the size and location of municipalities. The resources available also differ between municipalities. In relation to the resolution to increase walking and cycling, an investment programme was launched to support the implementation, and in $2018,3.5 \mathrm{M} €$ was distributed to 15 municipalities [65]. Most of the projects are, however, related to building high-quality infrastructure for cycling. Hence, it is important to emphasise measures also for increasing walking. Furthermore, the resolution could be complemented with measures targeting more specifically traffic safety and the role of motorised vehicles and travel habits in increasing active transport. Harmonising and unifying policymaking is important for implementing the related and necessary measures.

\section{Conclusion}

Traffic safety can be objectively described and assessed through traffic accidents, and the main focus has been on fatalities. In light of new common definitions and data collection procedures, the focus has lately shifted to include serious injuries. This study used pedestrian accident and exposure data to gain an overview of pedestrian safety in Finland, using the new data collection procedures based on MAIS3+ criteria. The main conclusions of the study are that there are differences in vehicle type, area type, accident location, current speed limit and road and lighting conditions between pedestrian fatalities and serious injuries. Pedestrian fatalities occur more often than serious injuries with trucks, on carriageways, in speed limit zones of $80 \mathrm{~km} / \mathrm{h}$, in small municipalities, and in rural areas. In contrast, serious injuries to pedestrians occur more often than fatalities with passenger cars, in wet road conditions, with streetlights lit, in temperatures from -3 to $3^{\circ} \mathrm{C}$, in speed limit zones of $40-70 \mathrm{~km} / \mathrm{h}$, on pedestrian crossings, and in inner urban areas.

In general, this study identified the main factors and differences between pedestrian fatalities and serious injuries where the other party was a motorised vehicle. However, these aspects represent only one part of the overall pedestrian traffic safety situation, since the analysis omitted accidents with other vehicles and pedestrian single accidents. Future studies should, therefore, identify differences in the severities also for these accidents to enable the deployment of suitable traffic safety strategies and actions. Given the need to understand the causes of serious injuries, and our poor understanding of the effects of road safety measures, future studies should also explore the effects of different road safety measures on serious injuries, because the results may differ from those relating to fatalities. In particular, emphasis should be placed on suitable road safety measures for all types of pedestrians, with special focus on elderly people. These future studies should explore the needs and requirements of elderly people, which could be taken into account when planning solutions and infrastructure aiming to improve pedestrian safety. As a result, road safety policies and measures targeting both fatalities and serious injuries could be deployed. Including serious injuries in traffic safety work shifts more of the responsibility to municipalities. Thus, there is a need for collaboration among different stakeholders on both a local, regional, national and European level. 


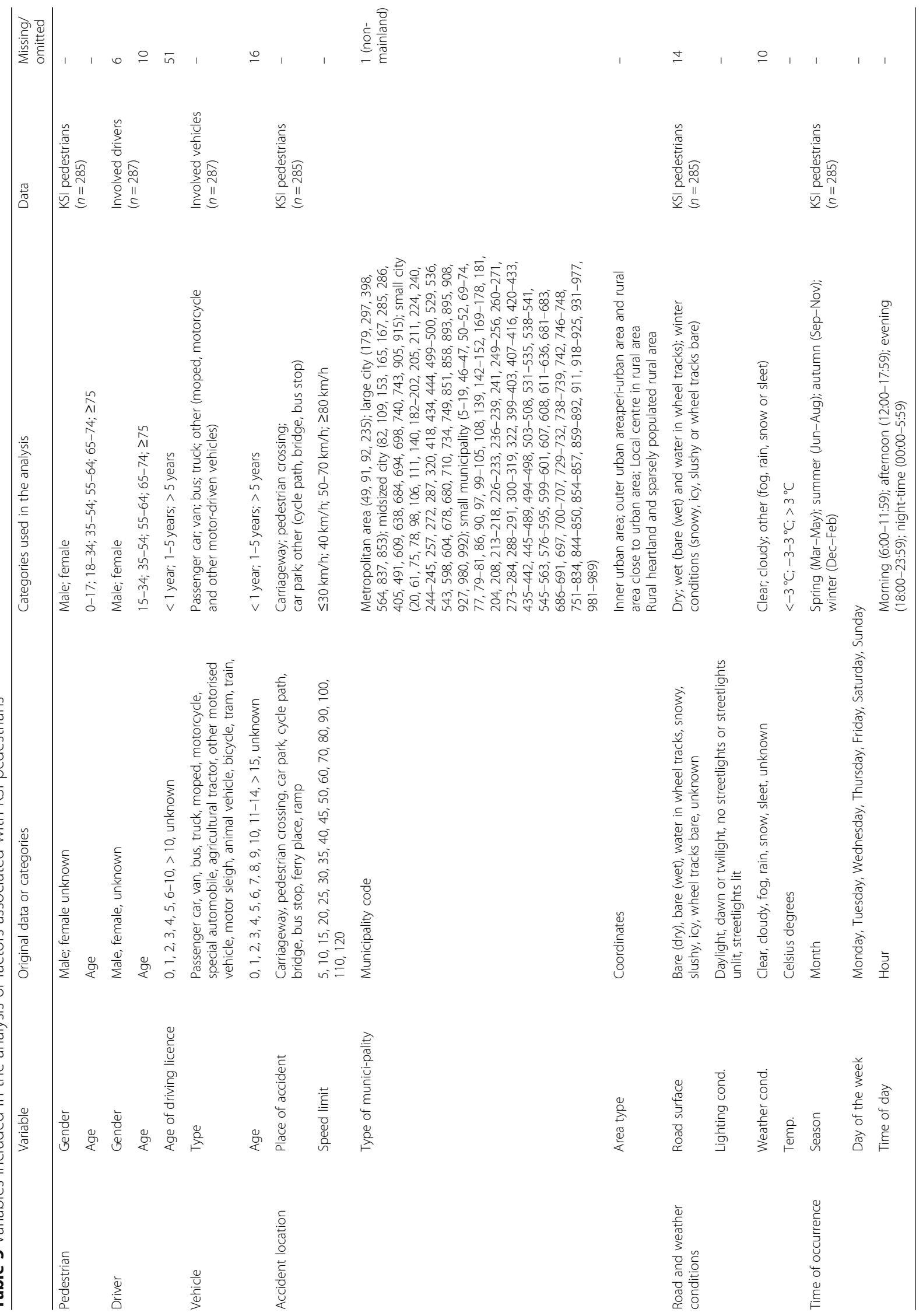




\section{Appendix 2}

Table 6 Relative shares and ratios of gender and age of pedestrians [18] and drivers [63] associated with KSI pedestrians

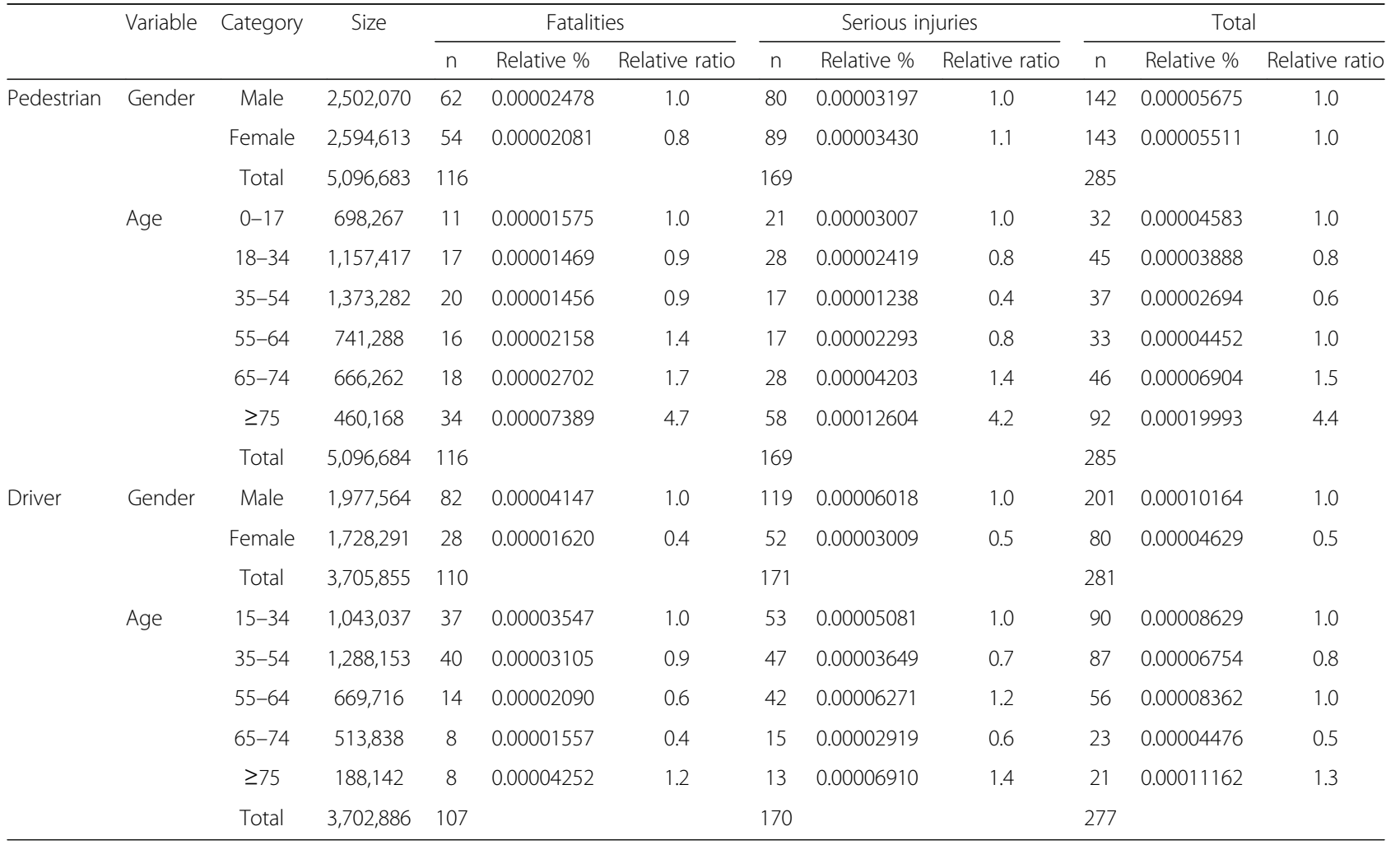




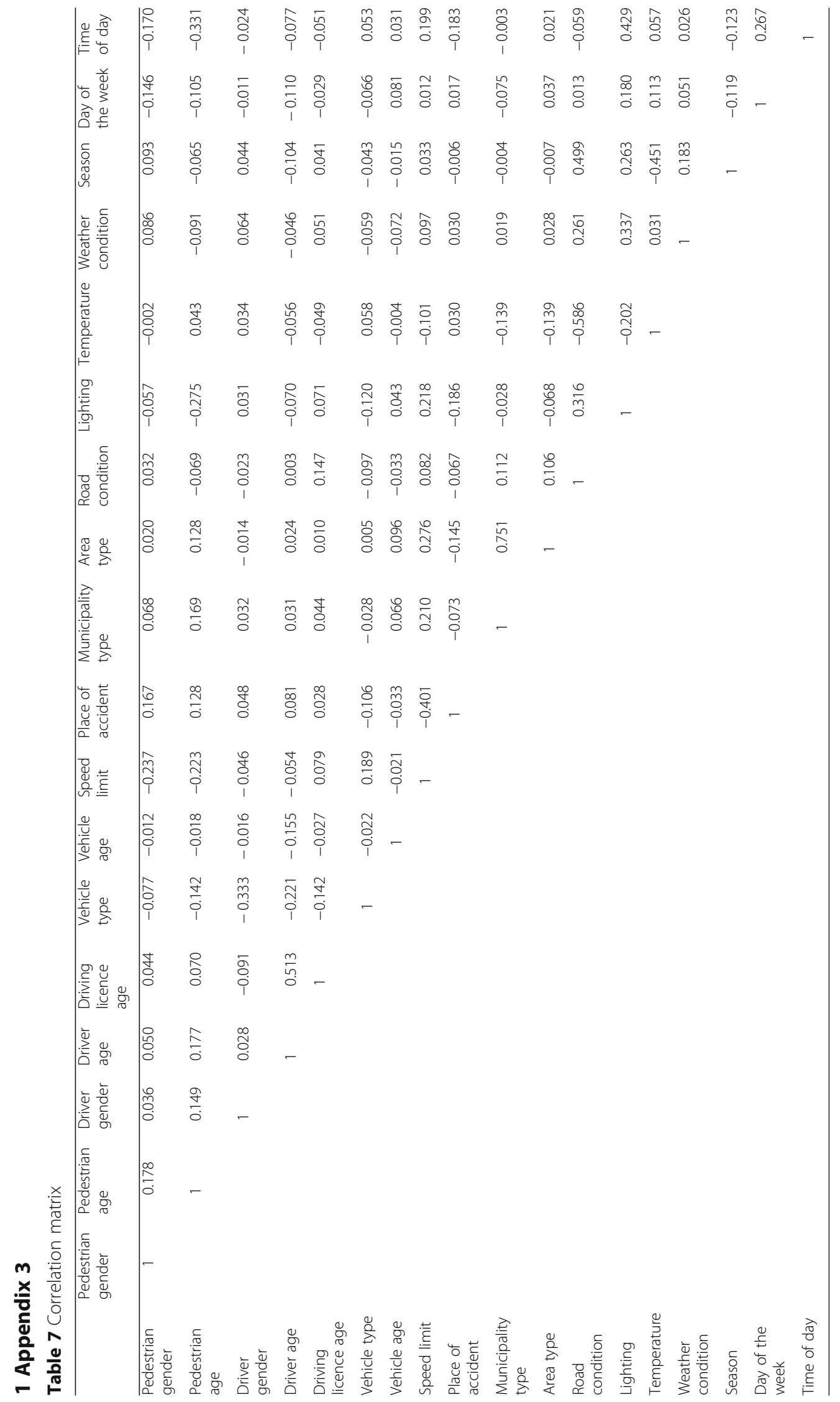


Furthermore, there is a need for further harmonisation of definitions and data collection procedures among the European member states. Only a unified and inclusive approach can help us achieve the transport policy objectives.

\section{Acknowledgements}

The authors wish to thank Harri Peltola for his helpful comments on an earlier draft of the manuscript, Esko Lehtonen for his help with logistic regression and Adelaide Lönnberg for editing the English.

\section{Authors' contributions}

FM was a major contributor in designing the work, analysing and interpreting the data and in writing the manuscript. AS and MM contributed in designing the work and interpreting the results, and revised the work. All authors read and approved the final manuscript.

\section{Funding}

This study was supported by the consortium programme Traffic Safety 2025. Participants in the programme in 2019 included the Finnish Transport Infrastructure Agency, the Finnish Transport and Communications Agency, Nokian Tyres Ltd., 21 Finnish cities (KEHTO-foorumi), and VIT Technical Research Centre of Finland Ltd. The consortium programme had no role in the design of the study, collection, analysis, and interpretation of data or in writing of the manuscript.

\section{Availability of data and materials}

The accident data used in this study were used solely with permission for the current study and are therefore not publicly available. The accident data can be requested from Statistics Finland.

The spatial datasets used in this study are available as open data in the National Land Survey of Finland repository, https:/tiedostopalvelu. maanmittauslaitos.fi/tp/kartta?lang=en and the Finnish Environment Institute repository, https://www.syke.fi/en-US/Open_information/Spatial_datasets The data on drivers and vehicles used in this study are available as open data in the Finnish Transport and Communications Agency repository http://trafi2.stat.fi/PXWeb/pxweb/en/TraFi/

\section{Competing interests}

The authors declare that they have no competing interests.

\section{Author details}

'VTT Technical Research Centre of Finland Ltd, P.O. Box 1000, Fl-02044 VTT Espoo, Finland. ${ }^{2}$ Spatial Planning and Transportation Engineering, Department of Built Environment, School of Engineering, Aalto University, Otakaari 4, 02150 Espoo, Finland.

Received: 4 July 2019 Accepted: 8 March 2020

Published online: 07 May 2020

\section{References}

1. Adminaite, D., Allsop, R., \& Jost, G. (2015). Making walking and cycling on Europe's roads safer, PIN flash report 29. Brussels: European transport Safety council (ETSC).

2. Auerbach, K. \& Schmucker, U. (2016). Country survey: State of the art of MAIS $3+$ assessment in the FERSI Member States and EU/EEA countries. FERSI working group "injury classification".

3. Baltes, M. R. (1998). Descriptive analysis of crashes involving pedestrians in Florida, 1990-1994. Transportation Research Record, 1636, 138-145.

4. Broughton, J. (1997). Road accident statistics. In M. Mitchell (Ed.), The Aftermath of Road Accidents (pp. 15-30). London: Routledge.

5. Clifton, K. J., Burnier, C. V., \& Akar, G. (2009). Severity of injury resulting from pedestrian-vehicle crashes: What can we learn from examining the built environment? Transportation Research-Part D, 14, 425-436.

6. Christiansen, L. B., Cerin, E., Badland, H., Kerr, J., Davey, R., Troelsen, J., \& Sallis, J. F. (2016). International comparisons of the associations between objective measures of the built environment and transport-related walking and cycling: IPEN adult study. Journal of Transport \& Health, 3, 467-478.

7. EC. (2007). Commission of the European Communities Green Paper: Towards a new culture for urban mobility, COM(2007) 551. European Commission, Directorate General for Energy and Transport, Brussels.

8. EC. (2013). Commission Staff Working Document. On the Implementation of Objective 6 of the European Commission's Policy Orientation on Road Safety 2011-2020 - First Milestone Towards an Injury Strategy. SWD(2013) 94 final. Brussels: European Commission.

9. Elvik, R. (2010). Why some road safety problems are more difficult to solve than others. Accident Analysis \& Prevention, 42(4), 1089-1096.

10. Elvik, R. (2011). Public Policy. In Porter, B. E. (Ed.) Handbook of Traffic Psychology, p. 471-483. Academic Press, Elsevier, London.

11. Elvik, R., \& Bjørnskau, T. (2019). Risk of pedestrian falls in Oslo, Norway: Relation to age, gender and walking surface condition. Journal of Transport \& Health, 12, 359-370.

12. Elvik, R., \& Bjørnskau, T. (2017). Safety-in-numbers: A systematic review and meta-analysis of evidence. Safety Science, 92, 274-282.

13. Elvik, R., Høye, A., Vaa, T., \& Sørensen, M. (2009). The handbook of road safety measures (2nd ed.). UK: Emerald Group Publishing Limited.

14. Eluru, N., Bhat, C. R. \& Hensher, D. A. (2008). A mixed generalized ordered response model for examining pedestrian and bicyclist injury severity level in traffic crashes. Accident Analysis \& Prevention, 40(3), 1033-1054.

15. European Commission. (2017). Annual Accident Report. European Commission, Directorate General for Transport, June 2017.

16. Adminaite, D., Calinescu, T., Jost, G., Stipdonk, H. \& Ward, H. (2018). Ranking EU Progression Road Safety. 12th Annual road safety PIN report. European Traffic Safety Council (ETSC). Brussels.

17. Finnish Environment Institute (2013). YKR Urban-Rural classification 2010 [Data file]. Retrieved from https://www.syke.fi/en-US/Open_information/ Spatial_datasets (Accessed 14 June 2019).

18. Finnish Transport Agency. (2018). National Travel Survey 2016. Statistics from the Finnish Transport Agency 1/2018 (p. 113). Helsinki: Finnish Transport Agency.

19. Finnish Government. (2016). Valtioneuvoston periaatepäätös tieliikenneturvallisuuden parantamiseksi - tiedosta liikenneturvallisuutta [the Finnish Government's resolution on road safety]. Retrieved from: https://valtioneuvosto.fi/paatokset/paatos?decisionld=0900908f804fd 1 b5 (Accessed 27 Feb 2019).

20. Finnish Government. (2018). Valtioneuvoston periaatepäätös kävelyn ja pyörälyn edistämisestä [the Finnish Government's resolution on promoting walking and cycling]. Retrieved from: https://valtioneuvosto.fi/paatokset/ paatos?decisionld=0900908f8059d525 (Accessed 27 Feb 2019).

21. Fontaine, H., \& Gourlet, Y. (1997). Fatal pedestrian accidents in France: A typological analysis. Accident Analysis \& Prevention, 29(3), 303-312.

22. Garber, N. J., \& Lienau, T. K. (1996). Traffic and highway geometric characteristics associated with pedestrian crashes in Virginia. (Report VTRC 96R29). Charlottesville: Virginia Transportation Research Council.

23. Gitelman, V., Balasha, D., Carmel, R., Hendel, L., \& Pesahov, F. (2012). Characterization of pedestrian accidents and an examination of infrastructure measures to improve pedestrian safety in Israel. Accident Analysis and Prevention, 44(1), 63-73.

24. Glász, A., \& Juhász, J. (2017). Car-pedestrian and car-cyclist accidents in Hungary. Transportation Research Procedia, 24, 474-481.

25. Jacobsen, P. L., Racioppi, F., \& Rutter, H. (2009). Who owns the roads? How motorised traffic discourages walking and bicycling. Injury Prevention, 15(6) 369-373.

26. Johansson, R. (2009). Vision zero - Implementing a policy for traffic safety. Safety Science, 47(6), 826-831.

27. Keall, M. D. (1995). Pedestrian exposure to risk of road accident in New Zealand. Accident Analysis \& Prevention, 27(5), 729-740.

28. Kim, E., Muennig, P., \& Rosen, Z. (2017). Vision zero: A toolkit for road safety in the modern era. Injury Epidemiology, 4(1), 1.

29. Kröyer, H. R. (2015). Accidents between pedestrians, bicyclists and motorized vehicles: Accident risk and injury severity, Doctoral dissertation. Lund: Lund University.

30. Lee, C., \& Abdel-Aty, M. (2005). Comprehensive analysis of vehiclepedestrian crashes at intersections in Florida. Accident Analysis \& Prevention, 37, 775-786.

31. Luoma, J., \& Sivak, M. (2014). Why is road safety in the US not on par with Sweden, the UK, and the Netherlands? Lessons to be learned. European Transport Research Review, 6(3), 295-302. 
32. Methorst, R. (2007). Assessing pedestrians' needs. The European COST 358 PQN project. Walk21, Toronto October $2^{\text {nd }} 2007$.

33. Methorst, R., Schepers, P., Christie, N., Dijst, M., Risser, R., Sauter, D., \& VanWee, B. (2017). 'Pedestrian falls' as necessary addition to the current definition of traffic crashes for improved public health policies. Journal of Transport and Health, 6, 10-12.

34. Ministry of Transport and Communications. (2018). Kävelyn ja pyöräilyn edistämisohjelma [Programme to promote walking and cycling]. Helsinki: Publications of the Ministry of Transport and Communications 5/2018. Ministry of Transport and Communications.

35. Mirzaei, E., Kheyroddin, R., Behzadfar, M., \& Mignot, D. (2018). Utilitarian and hedonic walking: Examining the impact of the built environment on walking behavior. European Transport Research Review, 10, 20.

36. Mohamed, M. G., Saunier, N., Miranda-Moreno, L. F., \& Ukkusuri, S. V. (2013), A clustering regression approach: A comprehensive injury severity analysis of pedestrian-vehicle crashes in New York, US and Montreal, Canada. Safety Science, 54, 27-37.

37. National Highway Traffic Safety Administration. (2015). Traffic Safety Facts 2013 Data - Pedestrians. Washington DC: US Department of Transportation Publication no. DOT-HS-812-124.

38. National Land Survey of Finland (2018). Municipal division [Data file] Retrieved from: https://tiedostopalvelu.maanmittauslaitos.fi/tp/kartta?lang= en (Accessed 14 June 2019).

39. Nilsson, G. (2004). Traffic Safety dimensions and the power model to describe the effect of speed on Safety. Lund: Bulletin 221, Lund Institute of Technology.

40. OECD. (2018). OECD Health Statistics 2018 Definitions, Sources and Methods. Retrieved from: http://www.oecd.org/els/health-systems/Table-ofContent-Metadata-OECD-Health-Statistics-2018.pdf (Accessed 27 Feb 2019).

41. Olszewski, P., Szagała, P., Wolański, M., \& Zielińska, A. (2015). Pedestrian fatality risk in accidents at unsignalized zebra crosswalks in Poland. Accident Analysis \& Prevention, 84, 83-91.

42. Owen, N., Humpel, N., Leslie, E., Bauman, A., \& Sallis, J. F. (2004). Understanding environmental influences on walking: Review and research agenda. American Journal of Preventive Medicine, 27(1), 67-76.

43. Partonen, T. 2016. Suicide prevention in Finland. Safety 2016 - From research to implementation. 12th world conference on injury prevention and safety promotion. 18-21 September 2016, Tampere Finland.

44. Peltola, H., Airaksinen, N., \& Sintonen, H. (2018). Serious injuries in road traffic. Accounting for serious injuries in road safety work. Helsinki: Research reports of the Finnish transport agency 2/2018 (p. 59). Finnish transport agency.

45. Peltola, H., \& Luoma, J. (2017). Comparison of road safety in Finland and Sweden. European Transport Research Review, 9, 3.

46. Polders, E., \& Briijs, T. (2018). How to analyse accident causation? A handbook with focus on vulnerable road users (Deliverable 6.3). Horizon 2020 EC project, InDeV. Hasselt: Hasselt University.

47. Rajalin, S. (2011). Tieliikenteen itsemurhat, sairauskohtaukset ja niiden tilastointi [suicides and seizures in traffic and the registering of them]. 9.8.2011. Helsinki: Finnish Road Safety council. Retrieved from: https://www.liikenneturva.fi/ sites/default/files/materiaalit/Tutkittua/Tutkimukset/2011_itsemurhat_ liikenteessa.pdf. (Accessed 14 June 2019).

48. Retting, R., Ferguson, S., \& McCartt, A. (2003). A review of evidence-based traffic engineering measures designed to reduce pedestrian-motor vehicle crashes. American Journal of Public Health, 93, 1456-1463.

49. Rosén, E., Stigson, H., \& Sander, U. (2011). Literature review of pedestrian fatality risk as a function of car impact speed. Accident Analysis \& Prevention, 43(1), 25-33.

50. Roudsari, B. S., Mock, C. N., Kaufman, R., Grossman, D., Henary, B. Y., \& Crandall, J. (2004). Pedestrian crashes: Higher injury severity and mortality rate for light truck vehicles compared with passenger vehicles. Injury Prevention, 10, 154-158.

51. Salenius, S. (2019). VAKVAM - Vakaviin vammautumisiin johtaneiden onnettomuuksien tiedonkeruuprojekti. IVAKVAM - data collection project for serious injury accidents]. In Presentation at traffic accident prevention expert group meeting II, 10.6.2019, Finnish institute for health and welfare, Helsinki, Finland.

52. Sammer, G., Gruber, C., Roeschel, G., Tomschy, R., \& Herry, M. (2018). The dilemma of systematic underreporting of travel behaviour when conducting travel diary surveys - A meta-analysis and methodological considerations to solve the problem. Transportation Research Procedia, 32 649-658.
53. Schepers, P., den Brinker, B., Methorst, R., \& Helbich, M. (2017). Pedestrian falls: A review of the literature and future research directions. Journal of Safety Research, 62, 227-234.

54. Sheskin, D. J. (2000). Handbook of parametric and nonparametric statistical procedures (2nd ed.). Chapman and Hall/CRC press, Boca Raton, FL.

55. Shinar, D., Valero-Mora, P., van Strijp-Houtenbos, M., Haworth, N., Schramm, A., De Bruyne, G., Cavallo, V., Chliaoutakis, J., Dias, J., Ferraro, D. E., Fyhri, A., Hursa Sajatovic, A., Kuklane, K., Ledesma, R., Mascarell, O., Morandi, A., Muser, M., Otte, D., Papadakaki, M., Sanmartín, J., Dulf, D., Saplioglu, M., \& Tzamalouka, G. (2018). Under-reporting bicycle accidents to police in the COST TU1101 international survey: Cross-country comparisons and associated factors. Accident Analysis \& Prevention, 110, 177-186.

56. Silla, A., \& Luoma, J. (2012). Main characteristics of train-pedestrian fatalities on Finnish railroads. Accident Analysis \& Prevention, 45, 61-66.

57. Statistics Finland (2018). Statistics on road traffic accidents. Retrieved from: http://tilastokeskus.fi/til/ton/index_en.html. (Accessed 11 Nov 2018).

58. Sze, N. N., \& Wong, S. C. (2007). Diagnostic analysis of the logistic model for pedestrian injury severity in traffic crashes. Accident Analysis \& Prevention, 39(6), 1267-1278.

59. Tay, R., Choi, J., Kattan, L., \& Khan, A. (2011). A multinomial logit model of pedestrian-vehicle crash severity. International Journal of Sustainable Transportation, 5(4), 233-249.

60. Tefft, B. C. (2013). Impact speed and a pedestrian's risk of severe injury or death. Accident Analysis \& Prevention, 50, 871-878.

61. Tingvall, C., \& Haworth, N. (1999). Vision zero - An ethical approach to safety and mobility. Proceedings of the 6th ITE International Conference on Road Safety and Traffic Enforcement; Beyond 2000, Melbourne, 6-7 September (1999).

62. Toroyan, T., Khayesi, M., \& Peden, M. (2013). Time to prioritise safe walking. International Journal of Injury Control and Safety Promotion, 20(2), 197-202.

63. Traficom (2019a). Valid driving licences by driver's licence class in 2014 2019. Retrieved from: http://trafi2.stat.fi/PXWeb/pxweb/en/TraFi/TraFi_ Ajokortit/010_ajok_tau_101.px/ (Accessed 12 Dec 2019).

64. Traficom (2019b). Vehicles in traffic by quarter in 2008 to 2019. Retrieved from: http://trafi2.stat.fi/PXWeb/pxweb/en/TraFi/TraFi_LLiikennekaytossa_ olevat_ajoneuvot/040_kanta_tau_104.px/ (Accessed 12 Dec 2019).

65. Traficom (2019c, January 8). Kävelyn ja pyöräilyn investointitukea myönnettiin 15 kunnalle [Investment support for walking and cycling was granted to 15 municipalities]. Retrieved from: https://www.traficom.fi/fi/ ajankohtaista/kavelyn-ja-pyorailyn-investointitukea-myonnettiin-15-kunnalle (Accessed 14 June 2019).

66. Valletta Declaration on Road Safety (2017). Ministerial Declaration on Road Safety. 29. March 2017. Valletta Malta EU2017.

67. Yannis, G., Papadimitriou, E., Chaziris, A., \& Broughton, J. (2014). Modeling road accident injury under-reporting in Europe. European Transport Research Review, 6(4), 425-438.

68. Zajac, S. S., \& Ivan, J. N. (2003). Factors influencing injury severity of motor vehicle-crossing pedestrian crashes in rural Connecticut. Accident Analysis \& Prevention, 35(3), 369-379.

69. Zeeger, C. V., \& Bushell, M. (2012). Pedestrian crash trends and potential countermeasures from around the world. Accident Analysis \& Prevention, 44(1), 3-11.

\section{Publisher's Note}

Springer Nature remains neutral with regard to jurisdictional claims in published maps and institutional affiliations. 